\title{
Team Emotion Diversity and Performance: The Moderating Role of Social Class Homogeneity
}

$\underline{\text { Authors }}$

Jiping Li, Hong Kong U. of Science and Technology, jiping.li@connect.ust.hk

Prithviraj Chattopadhyay, The U. of Auckland, p.chattopadhyay@auckland.ac.nz Elizabeth George, The U. of Auckland, e.george@auckland.ac.nz

Vishal Gupta, Indian Institute of Management, Ahmedabad, vishal@iima.ac.in 
Team Emotion Diversity and Performance: The Moderating Role of Social Class

\title{
Homogeneity
}

\begin{abstract}
Answering the call for research on the interplay between trait diversity and state diversity, we examine the interaction effect between emotion diversity and social class homogeneity on team information sharing and team performance. By integrating the multiple categorization arguments and categorization-elaboration model, we propose that social class homogeneity moderates the relationship between emotion diversity and information sharing in a way that emotion diversity hinders information sharing when social class homogeneity is high but elicits information sharing when social class homogeneity is low. In addition, information sharing has a stronger relationship with team performance when social class homogeneity is low. Our results support the propositions.
\end{abstract}

\section{Keywords:}

Emotion diversity; social class homogeneity; information sharing 


\section{Team Emotion Diversity and Performance: The Moderating Role of Social Class}

\section{Homogeneity}

The increasing adoption of team-based structure within modern organizations (Mathieu, Hollenbeck, van Knippenberg, \& Ilgen, in press) and the high heterogeneity in team members' demographic backgrounds, personality, and malleable characteristics (DiTomaso, Post, \& Parks-Yancy, 2007; Jackson \& Joshi, 2011) call for extensive research on team diversity (van Knippenberg \& Mell, 2016). Team diversity in its own right invites both opportunities and challenges to leverage the diverse perspectives, knowledge, and expertise that each member brings to foster high-quality performance, such as innovation and complex decision-making (De Dreu \& West, 2001; Kozlowski \& Bell, 2003). Therefore, the question of how team diversity affects team performance warrants research attention.

Indeed, a large amount of research attention has been devoted to examining how trait diversity affects team performance (van Knippenberg \& Mell, 2016). Traits diversity is understood as the variations in team members' traits, such as demographic characteristics (e.g., Dahlin, Weingart, \& Hinds, 2005) and personality (e.g., van Vianen \& De Dreu, 2001; Barsade, Ward, Turner, \& Sonnenfeld, 2000). However, largely neglected in diversity research is that the state diversity, defined as variations in team members' malleable characteristics, holds valuable lessons that the trait diversity research can benefit (van Knippenberg \& Mell, 2016: 136). A few existing studies on state diversity focus on the cognitive elements such as information distribution (e.g., Homan, van Knippenberg, van Kleef, \& De Dreu, 2007; van Ginkel \& van Knippenberg, 2009) and expertise diversity (e.g., Bonner, Baumann, \& Dalal, 2002). However, research on the effects of diversity in team 
members' emotion, which is a ubiquitous state-like characteristic experienced by team members, on team performance, remains salient.

Such omission is critical. First, emotion diversity constructs one essential aspect of the social reality. The fact that the work experience in teams is saturated with team members' feelings (Ashforth \& Humphrey, 1995; Menges \& Kilduff, 2015) invites emotion as an indispensable team composition factor (Barsade \& Gibson, 1998; Brief \& Weiss, 2002). Second, emotion diversity is of importance to team process and team performance because emotion itself plays an essential role in information processing and social interactions. As a short-term reaction to external stimuli (Ekman, 1999), emotion has an impact on individual thoughts via "processes, judgements, decision making and behaviors" and the profound effects it has on tasks that require deliberate information processing (Estrada, Isen, \& Young 1997; Forgas, 1995; Forgas \& George, 2001: 4). In addition, emotions signal information about individuals' intentions and attitudes and as a result form the basis of social interactions (Keltner \& Haidt, 1999). Moreover, the emotional experience yields more powerful effects than does cognitive reasoning in the interaction with members from a different social category in diverse groups (Tropp \& Pettigrew, 2005). The evidence above has crystallized into an effect that team diversity in emotions has on team task performance.

To address how emotion diversity could affect team performance, we borrow the two predominant perspectives in diversity research: social categorization perspective and information/decision-making perspective (Williams \& O’Reilly, 1998). The two, however, introduce competing predictions in the relationship between emotion diversity and team performance. According to social categorization perspective, the emotion diversity invokes 
"us-them" categorization and intergroup bias (Turner, Hogg, Oakes, Reicher, \& Wetherell, 1987). This in turn leads to conflicts (De Wit, Greer, \& Jehn, 2012) and harms group performance (Chatman, Polzer, Barsade, \& Neale, 1998). On the other hand, the information/decision-making perspective favors the "value-in-diversity" hypotheses (Cox, Lobel, \& McLeod, 1991:827), which contribute to the information integration (Homan et al., 2007) and enhances the effectiveness of team decision-making (Kooij-de Bode, van Knippenberg, \& van Ginkel, 2008). These competing perspectives raise two concerns to understand the relationship between emotion diversity and team performance: (1) identifying a mediating process that both perspectives can apply to; (2) eliciting a boundary condition that reconciles the two perspectives via the mechanism identified.

The current study addresses these two concerns. First, we use information sharing as the mechanism that can be explained by the two competing logics. The categorization-elaboration model (CEM, van Knippenberg et al., 2004) integrates the aforementioned two perspectives in a way that the intergroup bias following the social categorization process disrupts the information processing from the information/decision-making perspective. Inspired by this integrated model, follow-up studies have examined team diversity from both perspectives (e.g., Kearney, Gebert, \& Voelpel, 2009). We extend this model to state diversity, i.e., emotion diversity and examine the information sharing mechanism in the current study. We expect that emotion diversity has a negative effect on information sharing from the social categorization perspective or a positive effect from the information/decision-making perspective.

Second, we examine trait diversity as a boundary condition on the relationship between 
emotion diversity and team performance. Prior studies on the boundary conditions have elaborated on whether the benefits of "value in diversity" outweigh the costs of intergroup biases (see Guillaume, Dawson, Otaye-Ebede, Woods, \& West, 2015, for a review). However, few studies have examined the interplay between multiple diversity dimensions. The multifaceted nature of team diversity (Simons, Pelled, \& Smith, 1999) warrants an investigation into the interplay between trait diversity and state diversity, and whether and how the interplay shapes team process and team performance (Homan et al., 2007; Simons et al., 1999). Linking trait diversity with state diversity is therefore an important leap that moves the diversity research forward (van Knippenberg \& Mell, 2016).

In this study, we focus on social class diversity, one trait-like dimension and examine its moderating role. We borrow the logic from multiple categorization studies (Crisp \& Hewstone, 2007) and argue that social class plays a more primary role in categorization than does individual emotions, which are malleable and easy to change. We thus argue that a high level of social class homogeneity facilitates the positive effects of emotion diversity on information sharing, but a low level of social class homogeneity amplifies the negative effects of emotion diversity on information sharing. Moreover, we expect that a low level of social class homogeneity leverages the positive effect of information sharing on team performance because of the unique perspectives elicited from members' diverse social class backgrounds.

Figure 1 depicts our theoretical model of this study, which contributes to several aspects of diversity literature. First, we account for the under-examined role of state diversity in team process and team performance by showing that emotion diversity does have effects on team 
functioning. Second, we identify the boundary condition upon which the opposite effect of emotion diversity on team performance can be reconciled by taking into account the multifaceted nature of team diversity and investigating the interacting effect between emotion diversity and social class diversity (Simons et al., 1999). This investigation further answers calls to study the interplay between trait diversity and state diversity (van Knippenberg \& Mell, 2016). Moreover, we bring the social class background into diversity research as one dimension of team composition. This merits further investigation into research on team diversity and social class.

Insert Figure 1 about here

\section{THEORETICAL FOUNDATIONS AND HYPOTHESES}

\section{Emotion Diversity}

Emotion is intense and short-lived (Barsade \& Gibson, 2007), and can be defined as the configuration of psychobiological responses caused by an appraisal of a target or a situation, and often associated with subjective experiences and tendencies to behave in specific ways (Lazarus, 1991). It can be expressed through verbal and non-verbal behaviors (Ekman \& Friesen, 1974) and reflects the ways in which individuals perceive and interact with others in social contexts (Kemper, 1978).

Emotion diversity within a team refers to the degree to which individuals within a team experience shared emotions. It is manifested in two ways, positive emotion diversity and negative emotion diversity (Barsade \& Gibson, 1998). A team with positive emotion diversity consists of members whom experience positive emotions to different extents, with some members feeling relaxed and/or calm, and others experiencing happiness and/or ecstasy 
(Barsade \& Gibson, 2007). In contrast, a team with diverse negative emotions comprises members whom expose to negative emotions to various extents, with some feeling anger and/or frustrated, and others experiencing disappointed and/or sad (Barsade \& Gibson, 2007).

Although no attention is given to the effects of emotion diversity on performance, a body of literature has amassed on the subject of team diversity on team performance. Since a team is an information processing system (De Dreu, Nijstad, \& van Knippenberg, 2008; see Srikanth, Harvey, \& Peterson, 2016 for a review), we propose that information sharing serves as the mechanism through which team emotion diversity affects performance. This mechanism is also elucidated by the CEM (van Knippenberg et al., 2004), which suggests that both social categorization perspective and information/decision-making perspective employ the information sharing mechanism in the relationship between team diversity and team performance (Guillaume et al., 2015; Williams \& O’Reilly, 1998). Accordingly, we will review the literature on these two perspectives below and then suggest that the effect of emotion diversity on information sharing and on team performance.

\section{Emotion Diversity and Team Performance}

Social categorization perspective. Viewing diversity as a disruptive influence, social categorization perspective emphasizes that the process of social categorization based on certain attributes, such as race and nationality, invites inter-group bias (Tajfel \& Turner, 1979). Team members demonstrate positive response to in-group members who are in the same/similar social category to their own, psychologically through experiencing identification and commitment and behaviorally by displaying heightened communication and coordination (Turner et al., 1987). As a result, they are willing to share more information. 
In opposite, team members react to out-group members who are dissimilar to their own social category in a negative, if not an aloof manner, and as a result, they may share less information (van Knippenberg \& Mell, 2016). Following this logic, teams with low level of diversity have better integration, and thus perform well compared to teams with high level of diversity (e.g., Van der Vegt \& Bunderson, 2005). Extending this logic, we argue that team members who experience low level of emotion diversity are likely to experience the benefit of psychological integration and share more information with each other. Thus, we expect that high emotion diversity within a team, in forms of both positive emotion diversity and negative emotion diversity, hinder information sharing and in turn harm team performance.

Information/decision-making Perspective. In contrast, information processing/decision-making perspective points to the potential benefits of diversity, and suggests a positive relationship between emotion diversity and team performance (e.g., van Knippenbeg et al., 2004). From this perspective, diversity in individual characteristics, such emotional states, can serve as a resource pool because differences in team members' emotions are associated with differences in perceptions and information processing strategies, which in turn affect their ideas, opinions and perspectives which are geared towards team tasks (van Knippenberg \& Mell, 2016). For instance, positive emotional individuals unintentionally process information in a loose, unsystematic and less effortful way (George \& Zhou, 2007; Schwarz \& Clore, 2003); neutral state individuals assimilate information in a calm way (Lutz, Brefczynski-Lewis, Johnstone, \& Davidson, 2008); and negative emotional individuals carefully hold a cautious attitude and seize the opportunities that might emerge (Schwarz, Bless, \& Bohner, 1991). Given that team members can collectively identify and gather the 
diverse perspectives, the divergent perspectives foster information sharing (Harvey, 2014), which helps to enhance their team performance and decision-making (Kearney et al., 2009; Loyd, Wang, Phillips, \& Lount Jr, 2013). Thus, from information resources perspective, emotion diversity in a team fosters information sharing and enhances team performance.

\section{Boundary Condition: Social Class Homogeneity}

According to the CEM, the key to reconciling these two is to identify conditions under which either perspective applies (van Knippenberg et al., 2004). As the salience of intergroup bias from social categorization disrupts the information/decision-making process that is positively linked to information sharing (van Knipenberg et al., 2004), we investigate the condition under which the intergroup bias elicited by social categorization process based on emotion diversity is weakened or strengthened, so that the effect of emotion diversity from the information/decision-making perspective, on information sharing is fostered or inhibited.

Team composition is complex and multifaceted and so multiple dimensions of diversity co-exist, which allows the different dimensions of team diversity interplaying to shape the team process and team performance (Homan et al., 2007; Simons et al. 1999). Because the multiple categorization process between different diversity dimensions in which one dimension prevails over another by serving as the salient category based on which individuals group others, we argue that diversity in team members' traits can serve as a boundary condition for the relationship between emotion diversity and information sharing. The conventional wisdom of multiple categorization research (Crisp \& Hewstone, 2007) revolves around the hierarchical structure of categorization dimensions in which superordinate 
dimensions (e.g., gender and race) prevail over subordinate dimensions ${ }^{1}$ (e.g., dressing style) (Crisp \& Hewstone, 2001; Park \& Rothbart, 1982; Stangor, Lynch, Duan, \& Glas, 1992; Turner et al., 1987). Superordinate categorization dimensions (e.g., gender and race) are category labels that deliver highly informative cultural and social beliefs that are widely shared by others (Crisp \& Hewstone, 2001). As a result, individuals are more prone to categorize others based on these categories (Stangor et al., 1992). In contrast, subordinate categorization dimensions (e.g., dressing styles) are specific and less strongly associated with cultural and social beliefs. They are less likely to be used in the primary categorization (Turner et al., 1987). Accordingly, the superordinate dimensions, rather than the subordinate ones, provide primary reference points in the categorization process (Crisp \& Hewstone, 2007).

The features above of the two categories indicate that individual stable traits that are strongly associated with cultural and societal beliefs (DiTomaso et al., 2007; Ridgeway, 1991) are more likely to act as superordinate categorization dimensions. Individual malleable characteristics (e.g., emotions) that are weakly associated with cultural and societal beliefs are more likely to serve as subordinate categorization dimensions. Therefore, we argue the categorization on individual traits as opposed to emotions plays an essential role in the primary categorization. Specifically, when the trait diversity is low, the salience of similarity in trait dimension offsets the categorization bias from emotion diversity by diverting team members' attention to the salience of similarity in the superordinate category. On the contrary,

\footnotetext{
1 Admittedly, the superordinate-subordinate differentiation is context sensitive in the sense that the subordinate category can be superordinate in a specific condition (Messick \& Mackie, 1989). However, it is evident that "certain categories are generally superordinate", such as gender and race (Crisp \& Hewstone, 2001: 48).
} 
when the trait diversity is high which accelerates the categorization process, the intergroup bias derived from trait diversity further amplifies the intergroup bias from emotion diversity. An assumption here is that team members interact with each other rather than keep aloof attitudes towards outgroup members from a different social category based on that trait.

We examine whether social class, a type of trait diversity, can act as a superordinate categorization dimension and moderate the relationship between emotion diversity and information sharing. Social class diversity and social class homogeneity are used interchangeably in this study. Social class diversity/homogeneity refers to the extent to which team members share similar social class backgrounds. Social class is derived from both material resources (e.g., objective social economic status) and perceived rank vis-à-vis others (subjective social economic status) in a social hierarchy (Côté, 2011; Kraus, Piff, \& Keltner, 2009). It has profound effects on individual perception and reactions to the social world. Although social class has received little attention in diversity research, a few studies found the effects of social class differences on workplace behaviors (Côté, 2011; Gray \& Kish-Gephart, 2013). A key implication of these studies is that social class itself is an indispensable categorization dimension because of its deep roots in cultural and societal beliefs, which make the categorization on it sensible (i.e., normative fit, Turner et al., 1987; van Knippenberg et al., 2004). Moreover, social class is characterized as "class-specific repertoires of behavioral scripts" such as taste and style, based on which people recognize and easily make "ingroup-outgroup” categorization (Kraus, Piff, Mendoza-Denton, Rheinschmidt, \& Keltner, 2012: 547). Therefore, we argue that social class serves as a superordinate role in social categorization. In the following we detail the role it plays in the 
relationship between emotion diversity and group performance through information sharing.

\section{Emotion Diversity, Social Class Homogeneity, and Information Sharing}

When social class homogeneity is low, the categorization process based on social class is salient and shapes the primary group categorization in a team (cf. Stangor et al., 1992). The ingroup-outgroup bias derived from the social class diversity will be further amplified by high emotion diversity (Joshi \& Roh, 2009). This is because their perceived individual differences will be enhanced when team members with various social class backgrounds found that members face divergent emotional experience (cf., Phillips, Northcraft, \& Neale, 2006). Thus, they feel less psychologically committed and are less willing to share information. Therefore, we propose that in a team with a low level of the social class homogeneity, positive/negative emotion diversity harms information sharing because of the amplified categorization bias.

On the contrary, when team members share a high level of homogeneity in the social class background, such social categorization brings social integration benefits, such as commitment, identification, and perceived attraction (Guillaume, Brodbeck, \& Riketta, 2012). As discussed, social class serves as a superordinate categorization dimension. Once team members categorize each other as in-group members based on similar social class background, the variations in emotions does not trigger a strong "ingroup-outgroup" differentiation. As a result, they make more commitment to their relationships and tend to stress the benefits from the divergent perspectives elicited from different emotions (Crisp \& Hewstone, 2001; Park \& Rothbart, 1982). Accordingly, the negative effect of emotion diversity on information sharing from the social categorization perspective will be weakened, 
and the informational benefits of emotional diversity are likely to flourish when the social class diversity is at a lower level.

Hypothesis 1. Social class homogeneity moderates the relationship between positive emotion diversity and team information sharing in such a way that:

(a) Positive emotion diversity is negatively related to team information sharing when social class homogeneity is at a low level;

(b) Positive emotion diversity is positively related to team information sharing when social class homogeneity is at a high level.

Hypothesis 2. Social class homogeneity moderates the relationship between negative emotion diversity and team information sharing in such a way that:

(a) Negative emotion diversity is negatively related to team information sharing when social class homogeneity is at a low level;

(b) Negative emotion diversity is positively related to team information sharing when social class homogeneity is at a high level.

\section{Information Sharing, Social Class Homogeneity, and Team Performance}

We also propose that social class diversity can serve as a contingency upon which the effect of information sharing on performance (see Mesmer-Magnus \& DeChurch, 2009 for a meta-analysis) can be strengthened or weakened by such diversity. Information sharing is defined as "the degree to which team members share information with each other" (Johnson, Hollenbeck, Humphrey, \& Ilgen, 2006). It acts as a key process in which team members collectively utilize their informational resources to enhance team performance. High information sharing indicates that the information spreads broadly among team members in 
the process of their communications pertinent to team goals, coordination, and the like (Jehn $\&$ Shah, 1997). Such openly shared information among teams promotes positive team climatic states such as higher trust and team cohesion, which in turn improve social-emotional outcomes, thereby enhancing team task performance (Beal, Cohen, Burke, \& McLendon, 2003). However, whether the shared information can promote positive social-emotional outcomes and team performance largely hinges on several contingencies, such as team discussion structure, task types and evaluation criteria of team performance (Mesmer-Magnus \& DeChurch, 2009). One of the important contingencies is the extent to which the information being shared is unique (Mesmer-Magnus \& DeChurch, 2009).

Extending their findings, we argue that social class diversity moderates the main effect of information sharing on team performance because social class diversity denotes the extent to which the information shared within teams is unique. Social class diversity implies the potentiality of diverse perspectives and mental models that invoke alternative opinions for problem solving and divergent interpretations of social reality (e.g., Côté, 2011; Gray \& Kish-Gephart, 2013; Kraus et al., 2009; Kraus et al., 2012). For instance, Kraus and his colleagues (2012) revealed the distinct cognitive patterns of high- versus low- social class individuals in the sense that individuals from low social class see more constraints in the context than those from high social class do. Kish-Gephart and Campbell (2014) found that CEOs from the high social class background are more likely to take risks in making strategic decisions.

When the social class homogeneity within a team is high, the more information team members share, the more likely they found the information to be less unique (Phillips et al., 
2006). This is because common values, behavioral repertories, and class-linked cognitive patterns (Kraus et al., 2012) make it easy for team members to form a shared mental model. In addition, according to the information sampling bias model, individuals favor the information that is similar to what they already hold (Stasser \& Titus, 1985). As such, teams with similar social class background risk reaching a suboptimal solution because team members are less likely to fully explore repertories of unshared information but spend time discussing the shared information. Thus, the positive effect of information sharing on team performance is compromised in a team with a high level of homogeneity in members' social class background.

In contrast, social class heterogeneity can enhance the positive effects of information sharing on team performance. Given a high level of information shared among team members, the categorization bias generated from social class heterogeneity is not salient. Instead, team members' diverse social class backgrounds not only bring in divergent perspectives but also elicit the expectations of divergent perspectives (Loyd et al., 2013). As such, team members are likely to enlarge the pool of task-relevant knowledge and opinions that are diverse and non-redundant. To the extent that team tasks are complex and superior solutions to complex tasks require members to synthesize unique information, teams who share unique information are likely to outperform those who share the commonly held information. This argument echoes with the meta-analysis results that the effective sharing of information contributes to team performance, to the extent that the shared information is non-redundant (Mesmer-Magnus \& DeChurch, 2009). Thus, the positive effect of information sharing on group performance is stronger when the team's social class homogeneity is low. 
Hypothesis 3. Social class homogeneity weakens the positive relationship between information sharing and team performance in such a way that the lower the social class homogeneity, the stronger the positive relationship between information sharing and team performance.

\section{The Conditional Mediating Role of Information Sharing}

With previous hypotheses in place, we propose the moderated mediation model of emotion diversity and team performance. Positive/negative emotion diversity enhances information sharing in a team with high social class homogeneity and impedes information sharing in a team with low social class homogeneity. These impacts on information sharing subsequently influence team performance, with a stronger positive influence in a team with low social class homogeneity than that in a team with high social class homogeneity.

Therefore, we expect an indirect relationship between positive/negative emotion diversity and team performance, moderated by team social class homogeneity, and mediated by information sharing.

Specifically, when a team is diverse in social class (i.e., low social class homogeneity), positive/negative emotion diversity is indirectly and negatively related to team performance via information sharing. As positive/negative emotion diversity increases, the high level of social class diversity amplifies the categorization bias (Turner et al., 1987) elicited by different emotion states, which undermines information sharing within the team. Thus, the process of information sharing within teams is hindered. Moreover, the diverse perspectives associated with different social class background could leverage the positive effects of information sharing on team performance. We, therefore, expect a negative relationship 
between emotion diversity and team performance via information sharing when the social class homogeneity is at a lower level.

On the other hand, when a team is homogeneous in social class, positive/negative emotion diversity is indirectly and positively related to team performance via information sharing. The homogeneity in social class enhances social integration that counteracts the categorization bias elicited by positive/negative emotion diversity. Thus, such teams are more likely to engage in information sharing, which contributes to group performance in a weaker way when the social class homogeneity is high. Thus,

Hypothesis 4a. Positive emotion diversity has a negative indirect relationship with team performance via information sharing when social class homogeneity is at a lower level. Hypothesis 4b. Positive emotion diversity has a positive indirect relationship with team performance via information sharing when social class homogeneity is at a higher level. Hypothesis 5a. Negative emotion diversity has a negative indirect relationship with team performance via information sharing when social class homogeneity is at a lower level. Hypothesis 5b. Negative emotion diversity has a positive indirect relationship with team performance via information sharing when social class homogeneity is at a higher level.

\section{METHODS}

\section{Sample and Procedures}

Our sample consisted of 452 participants made up of Master of Business Administration (MBA) Indian students, whom were allocated into 75 project teams in five sessions. Each session had 15 teams. The team size ranged from 5 to 7 members $($ mean $=5.92, S D=0.36)$. 444 students completed the survey with a response rate of 98\%. Among them, 68 percents 
were males and 32 percent were females; 93 percent held an undergraduate degree, and 7 percent had obtained another postgraduate degree before they joined the MBA program. The average age was 23.03 years $(S D=1.74)$. The mean number of years of full-time employment was $1.08(S D=1.32)$. They came from 24 of 36 states and union territories of India.

We collected data at four phases. First, students attending the MBA orientation program received a letter inviting them to participate in the study, explaining the purpose of the study and assuring them of the confidentiality of all information collected. Students interested in participating in the study signed a consent form and responded to a survey about their demographic characteristics, academic background, and work experience as well as individual characteristics as control variables. Three days after the first survey, students commenced on a group project, which lasted the entire three months of the academic term. At Phase 2 which was around the end of the second week of term, data on team members' emotions and perceived homogeneity on the social class background were collected. We also collected individual emotion trait as control variables at Phase 2. At Phase 3, we collected data on information sharing in the middle of the term. Other team process variables such as team cohesion and team communication quality were also collected at Phase 3 as control variables. At the last phase when the team project finished, we collected the team performance data.

\section{Measures}

Emotion diversity. We measured both positive and negative emotion diversity. We used the 22-item scale from Barrett and Russell (1998), and Seo and Barrett (2007) to assess 
participants' emotions they felt during the first team meeting. They rated on a scale from " 1 . not at all" to "7. extremely so". The positive emotions items include happy, satisfied, excited, joyful, enthusiastic, proud, interested, calm, relaxed (Cronbach's Alpha =.98). The negative emotions items include sad, disappointed, irritated, afraid, angry, nervous, frustrated, depressed, and tired (Cronbach's Alpha $=.99)$. CFA results supported that the two-factor model fits the data better $($ Chi-Square $=417.33, p<.00, C F I=.92, T F I=.91$, RMSEA $=.07$, $S R M R=.06)$ than the single-factor model (Chi-Square $=857.76, p<.00, C F I=.80, T F I$ $=.76, R M S E A=.11, S R M R=.11)$. The standard deviations of all the team members' positive emotions and negative emotion were counted as the team's positive emotion diversity score and negative emotion diversity score, respectively (Alison, 1978).

Social class homogeneity. We measured social class homogeneity by the perceived homogeneity in team members' caste. An individual has perception of him- or herself as belonging to high social class or low social class in a social context (Kraus et al., 2009), and based on that the individual perceives the similarity of social class of him- or herself to that of others, and categorize those similar people accordingly. Therefore, social class homogeneity can be measured by subjective perceptions. Due to the nature of our context (i.e., social class in India), we used "caste" as a proxy for social class. Caste is a system in which social class is classified in India. According to the studies on Indian caste, "objectively ascertaining the criteria to understand the caste system is a challenging proposition" in an academic sense (Kumar, 2016 ${ }^{2}$ ), but people living with this system have developed their own approaches to making judgments on others' caste, such as through their job, language, and

\footnotetext{
2 http://www.epw.in/journal/2016/50/discussion/caste-contemporaneity-and-assertion.html
} 
style. It is, therefore, sensible to assess the subjective perception of caste homogeneity as a way to measure social class homogeneity.

We measured social class homogeneity by asking the participants' perceptions of the similarity of their own caste vis-à-vis other team members (Liao, Chuang, \& Joshi, 2008), on a 7-point scale from "1. very similar" to "7. very dissimilar". We checked the within-group inter-rater agreement $\left(r_{\mathrm{wg}}\right)$. The mean of $\mathrm{r}_{\mathrm{wg}}$ score was .82 , which is above the .70 threshold (James, Demaree, \& Wolf, 1984). We also checked the intra-class correlation $\left(\operatorname{ICC}_{(1)}\right)$, the score of which was .10, close to the .12 threshold (e.g., Kirkman, Chen, Farh, Chen, \& Lowe, 2009). Accordingly, we aggregated each members' ratings on their perceived caste similarity to team members as the team's social class homogeneity score.

Team information sharing. We used the 3-item scale from Bunderson \& Sutcliffe (2002) to measure information sharing. Reliability score of this scale was .79 in our sample. The sample items include "Information used to make key decisions was freely shared among the members of the team." The participants rated on a scale from "1. strongly disagree" to "7. strongly agree". The within-group agreement $\left(\mathrm{r}_{\mathrm{wg}}=.82\right)$ and intra-class correlation scores $\left(\mathrm{ICC}_{(1)}=.13\right)$ justified our aggregation of team members' ratings as a team-level score of information sharing.

Team performance. The team performance was based on two assignments that the project teams accomplished in the first term. One assignment was an online simulation game that required team members' intensive discussion and complex decision-making. The simulation results were quantitative by nature and the evaluation was based on the final cash the team ended up with. The team with the highest cash was given 10 points. The team with 
the lowest cash was given 4 points ( 4 points were given because they participated). The rest were intrapolated between the two scores (4 and 10). The other one was a written report on organizational networks. Instructors did the evaluation on the written report on a score of 1 to 5. Three instructors were in charge of all the grading based upon a common framework and set of rules. Each team' total scores were the sum of the simulation scores and written report, and weighted by $15 \%$, which was the percentage of the team performance takes in individuals' total performance.

\section{Control Variables}

Team composition variables. Multiple demographic features can be the categorization criteria to classify people into ingroups and outgroups. Because we were interested in the particular effects of emotion diversity and social class diversity, we controlled for the effects of other team composition variables, including diversity in demographic characteristics, personality traits, and individual propensity. We controlled for each teams' gender diversity, age diversity, tenure (the year of full-time employment before the MBA program) diversity, and major diversity. Gender diversity and major diversity were calculated using Blau Index (Harrison \& Klein, 2007); age diversity and tenure diversity were calculated by the standard deviation (Alison, 1978). We also controlled for the team composition on individual traits that potentially contribute to team information sharing, such as extraversion (Krämer \& Winter, 2008), openness to experience (Matzler, Renzl, Muller, Herting, \& Morradian, 2008), and learning goal orientation (Wang \& Noe, 2009). The means and standard deviations of these variables were both included to capture the effects (e.g., Bell, 2007). We measured individual extraversion and openness to experience using the "Big-Five" personality scale by John and 
Srivastava (1999), and the learning goal orientation using the scale by Grant and Dweck (2003). The reliability scores of these scales were $.85, .72$ and .88 , respectively.

Team process variables. We also controlled for other team process variables that might be subjected to the effects of emotion diversity and also influence team performance, such as team cohesion (Webber \& Donahue, 2001) and team communication quality (Wegge \& Schmidt, 2009). Team cohesion was measured using O'reilly, Caldwell, and Barnett's (1989) scale, and team communication quality using Knapp, Ellis, and Williams' (1980) scale. The reliability scores were .80 and .92 , respectively.

Positive/negative emotions and affective traits. As our focus was to examine the effect of positive/negative emotion diversity, we controlled for the group mean of positive/negative emotion within the team, to rule out the possibility that the effects of positive/negative emotion diversity may be contingent on the mean level of positive/negative emotions. In addition, team members' mean level and variance in positive affectivity and negative affectivity were also controlled (cf. Barsade et al., 2000). The positive affectivity and negative affectivity were measured using the same scale as we measured the emotional experience (Barrett \& Russell, 1998; Seo \& Barrett, 2007). Team members rated it on the extent to which each affective adjective described the feelings they experienced in general rather than in the most recent meeting. The reliability scores for positive/negative affectivity were .92 and .90 , respectively.

Instructor. Besides, we also controlled for the effects of different instructors' subjective evaluation tendency on team performance by using dummy codes to indicate that Section 1 and Section 2 had the same instructor, and Section 4 and Section 5 had the same one. 


\section{RESULTS}

\section{Data Analysis Strategies}

Given that the project teams in our sample were nested in five sections, the sample size at the higher level (i.e., 5 units) was too small, which leads to biased estimation in multilevel modeling (Maas \& Hox, 2005). We thus adopted the Ordinary Least Square (OLS) regression rather than the multilevel modeling as the proper approach to analyzing our data. To test our hypotheses, we first standardized all the variables, and computed interaction terms between (i) positive/negative emotion diversity and social class homogeneity, and (ii) information sharing and social class homogeneity. We also examined the variance inflation factor (VIF) to assess the extent of multicollinearity problem that might exist in our study. We found that the VIFs for all variables were below 5, which indicated that multicollinearity was not a concern. We tested Hypothesis 1a-3 using the approach suggested by Aiken and West (1991). To test the conditional indirect effects in Hypotheses $4 a-5 b$, we firstly calculated the product terms as suggested by Edwards and Lambert (2007), and then assessed them by the bootstrapping with 20,000 repetitions to construct 95\% Monte Carlo confidence intervals (Bauer, Preacher, \& Gil, 2006; Selig \& Preacher, 2008).

\section{Descriptive statistics}

Table 1 displays the descriptive statistics results, including means, standard deviations and pairwise correlations between all variables.

$$
\text { Insert Table } 1 \text { about here }
$$

\section{Hypothesis Testing}

Hypotheses $1 \mathrm{a}-1 \mathrm{~b}$ state that the interaction between positive emotion diversity and social 
class homogeneity affects information sharing such that positive emotion diversity is negatively related to information sharing when the social class homogeneity is low, but positively related to information sharing when the social class homogeneity is high. Following the procedures by Aiken and West (1991), we tested the moderation effect. Model 2 in Table 2 shows that the interaction term between positive emotion diversity and social class homogeneity was significantly related to information sharing $(b=.13, p<.05)$. We plotted the interaction for teams with a lower or higher level of social class homogeneity using 1 s.d. below and above the mean (Aiken \& West, 1991). As shown in Figure 2, positive emotion diversity has a more negative effect on information sharing for teams with a lower level, rather than a higher level of social class homogeneity. The simple slopes analysis using the approach proposed by Bauer and Curran (2005), and Preacher, Curran and Bauer (2006) revealed that the effect of positive emotion diversity on team information sharing was significant when social class homogeneity was low $(b=-.28, p<.01)$ rather than high $(b=$ $-.02, p>.05)$. Thus, our Hypothesis 1a was supported, but Hypothesis $1 \mathrm{~b}$ was not.

Insert Table 2 and Figure 2 about here

We used a similar approach to test Hypotheses 2a-2b. As shown in Model 4 in Table 2, the interaction term between negative emotion diversity and social class homogeneity on information sharing was significant $(b=.20, p<.01)$. Figure 3 displays the interaction pattern. It shows that negative emotion diversity was positively related to information sharing when the social class homogeneity was at a higher level. However, emotion diversity is negatively related to information sharing when the social class homogeneity was at a lower level. The simple slope test supported that the effect of negative emotion diversity on 
information sharing was significant when the social class homogeneity was at a lower level $(b$ $=-.25, p<.05)$ rather than at a higher level $(b=.14, p>.05)$. Accordingly, Hypothesis $2 \mathrm{a}$ was supported, but Hypothesis $2 \mathrm{~b}$ was not. However, the regions of significance test (Bauer \& Curran, 2005; Dawson, 2014; Johnson \& Neyman, 1936) indicated that the simple slope of the high condition became significant when social class diversity was 1.66 s.d. above the mean $(b=.27, p=.05)$.

Insert Figure 3 about here

Hypothesis 3 states that the positive relationship between information sharing and team performance is stronger when the social class homogeneity is at a lower level rather than at a higher level. Model 6 in Table 2 indicates that the interaction term between information sharing and team performance was significant $(b=-.06, p<.05)$. The interaction pattern (see Figure 4) shows that information sharing was positively related to team performance when the social class homogeneity was at a lower level, but negatively related to team performance when the social class homogeneity was at a higher level. The simple slope test further supported the significance of the lower social class homogeneity condition $(b=.10, p<.05)$ rather than the higher social class homogeneity condition $(b=-.02, p>.05)$. The results indicated that the positive relationship between information sharing and team performance was stronger when the social class homogeneity was low rather than high, supporting Hypothesis 3.

Insert Figure 4 about here

We used the Monte Carlo Method for Assessing Mediation (MCMAM, Selig \& Preacher, 
2008 ) to test the indirect effect of emotion diversity on team performance. This method is parallel to the parameter-based bootstrapping in that it does not require a normal distribution for indirect effects. We used the R-package and followed the R code provided by Preacher and his colleagues' website ${ }^{3}$. The MCMAM results revealed that, the conditional indirect effect between positive emotion diversity and team performance via information sharing was significant in a negative way when team social class homogeneity was low (95\% CI: -.070, -.002), but non-significant when team social class homogeneity was high (95\% CI: $-.011, .013)$. On the other hand, the condition indirect effect between negative emotion diversity and team performance via information sharing was also significant in a negative way when team social class homogeneity was low (95\% CI: -.066, -.001), but non-significant when team social class homogeneity was high $(95 \%$ CI: $-.023, .013)$. Thus, our Hypothesis $4 \mathrm{a}$ and Hypothesis 5a were supported, but Hypothesis $4 \mathrm{~b}$ and Hypothesis $5 \mathrm{~b}$ were not.

\section{DISCUSSION}

In the current study, we address an important while unsubstantiated question in diversity research on how emotion diversity affects team information sharing and in turn team performance, under a contingency of social class diversity within teams. There are inconsistent results from prior studies that diversity within a team may lead to both positive and negative level of information sharing and in turn task performance (van Knippenberg et al., 2004), and emotion diversity is no exception based on our arguments. Taking into account the multifaceted nature of team diversity (Simons et al., 1999), we theorized that social class diversity acts as a boundary condition upon which the social categorization effects of emotion diversity get amplified or alleviated and thus emotion diversity could hinder or foster

\footnotetext{
${ }^{3}$ http://www.quantpsy.org/medmc/medmc.htm
} 
information sharing. As our analysis shows, when social class homogeneity is low, emotion diversity inhibits information sharing and consequently task performance due to the amplified social categorization perceived by team members. In addition, we question the oversimplification of the baseline effect of information sharing on task performance, and therefore extend previous studies (e.g., Mesmer-Magnus \& DeChurch, 2009) by suggesting another boundary condition, social class homogeneity. Our results indicate a positive moderating effect such that when social class homogeneity is low, the more information is shared, the higher the task performance.

\section{Theoretical Implications}

Our work extends research in team diversity in two substantive ways. First, it goes beyond existing studies on team diversity that largely focuses on diversity in demographic attributes, by empirically demonstrating that emotion diversity as an indispensable dimension of team state diversity (van Knippenberg \& Mell, 2016). Thus the malleable attributes of team members as composition variables do exert influences on team functioning. A critical contribution of investigating emotion diversity in this study is that emotion diversity formed at the initial stage of team development (e.g., Gersick, 1988) has effects on the team process and outcomes at the later stages. It also supports the notion that although emotions are short-term reactions to external stimuli (Ekman, 1999), they can shape an individual's judgment and decision-making over a longer term (cf. Forgas \& George, 2001). As such emotion diversity has effects on team information sharing and team performance.

Second, due to the multifaceted nature of diversity effects, we identify social class homogeneity as one boundary condition to reconcile the competing predictions of the 
relationship between emotion diversity and information sharing from social categorization and information/decision-making perspective (van Knippenberg et al., 2004). Our integration of state diversity (i.e., emotion diversity) and trait diversity (i.e., social class diversity) brings critical insights that different dimensions of team diversity do interact to influence team process and outcomes. This insight is important because it enhances our understanding of the effects of team diversity by shifting our attention from considering a particular dimension of team diversity to considering multiple dimensions as interacting influences. Prior studies did shed light on the idea of the interacting effect among multiple dimensions of diversity but they used lab experiments (e.g., Homan et al., 2007; Phillips et al., 2006). Our study extends the interacting effects using field survey design.

Moreover, it is also noteworthy that the observed interaction pattern between emotion diversity and social class homogeneity is consistent with our theorization of multiple categorization effects (e.g., Crisp \& Hewstone, 2007) and CEM (van Knippenberg et al., 2004). The findings support our argument that when the social class homogeneity is low, the social categorization effect based on social class amplifies the same effect of emotion diversity, which disrupts the information/decision-making process of emotion diversity that may potentially contribute to information sharing. Arguably, our results indicate that when the social class homogeneity is at a higher level (i.e., over 1.66 s.d. above the mean in our sample), negative emotion diversity is positively related to information sharing. It echoes our argument that the categorization based on social class, which is a primary categorization dimension according to multiple categorization arguments (e.g., Crisp \& Hewstone, 2007), prevails over emotions by serving as the salient categorization dimension. Consequently, the 
emotion diversity elicits more information sharing, because the categorization bias based on emotions is not salient and the diverse information-processing perspectives indicated by diverse emotions are accessible to members. Our integration between multiple categorization and CEM provide insights to understand the interacting effects between multiple dimensions of team diversity. Future research may substantiate this analysis further.

\section{Practical Implications}

Making diverse team function effectively is an increasing challenge for practice (cf. Milliken \& Martins, 1996; van Knippenberg \& Schippers, 2007; van Knippenberg \& Mell, 2016). The present findings shed light on the importance of understanding that challenge. Our findings illustrate that diverse teams not only need to know how to manage members' demographic dimensions in terms of engaging members in the information sharing, but also to manage the diversity of their emotions (Sanchez-Burks \& Huy, 2009).

Moreover, out results also demonstrate that it is critical to take into account the multifaceted nature of diversity to effectively manage its challenges. Merely considering the effects of one type of diversity does not allow supervisors to gain a comprehensive understanding of its implications. Our study further calls managers attention to the overlapping or cross-cutting (e.g., Hofman et al., 2007) issue of multiple dimensions of team diversity.

\section{Limitations and Future Research Directions}

The current design is not without its limitations that merit further research. First, we test our conceptual model using MBA project teams. The short-term team project might make the effects of emotions more salient. Future research may further examine the effects of emotion 
diversity in teams with a long tenure and see whether the pattern of results found in our study is replicated in organizations. In addition, our study supports the notion that multiple dimensions of diversity interact to influence the team process and team outcomes by using emotion diversity and social class homogeneity as the illustrations. Future research could further extend this notion to other combinations.

\section{REFERENCES}

Aiken, L. S., West, S. G., \& Reno, R. R. 1991. Multiple regression: Testing and interpreting interactions. Thousand Oaks, CA: Sage.

Allison, P. D. 1978. Measures of inequality. American Sociological Review, 43: 865-880.

Ashforth, B. E., \& Humphrey, R. H. 1995. Emotion in the workplace: A reappraisal. Human Relations, 48: 97-125.

Barrett, L. F., \& Russell, J. A. 1998. Independence and bipolarity in the structure of current affect. Journal of Personality and Social Psychology, 74: 967-984.

Barsade, S. G., \& Gibson, D. E. 1998. Group emotion: A view from top and bottom. Research on Managing Groups and Teams, 1: 81-102.

Barsade, S. G., \& Gibson, D. E. 2007. Why does affect matter in organizations? The Academy of Management Perspectives, 21: 36-59.

Barsade, S. G., Ward, A. J., Turner, J. D., \& Sonnenfeld, J. A. 2000. To your heart's content: A model of affective diversity in top management teams. Administrative Science Quarterly, 45: 802-836.

Bauer, D. J., \& Curran, P. J. 2005. Probing interactions in fixed and multilevel regression: Inferential and graphical techniques. Multivariate Behavioral Research, 40: 373-400.

Bauer, D. J., Preacher, K. J., \& Gil, K. M. 2006. Conceptualizing and testing random indirect effects and moderated mediation in multilevel models: new procedures and recommendations. Psychological Methods, 11: 142-163.

Beal, D. J., Cohen, R. R., Burke, M. J., \& McLendon, C. L. 2003. Cohesion and performance in groups: a meta-analytic clarification of construct relations. Journal of Applied Psychology, 88: 989-1004.

Bell, S. T. 2007. Deep-level composition variables as predictors of team performance: a meta-analysis. Journal of Applied Psychology, 92: 595-615.

Bonner, B. L., Baumann, M. R., \& Dalal, R. S. 2002. The effects of member expertise on group decision-making and performance. Organizational Behavior and Human Decision Processes, 88: 719-736.

Brief, A. P., \& Weiss, H. M. 2002. Organizational behavior: Affect in the workplace. Annual Review of Psychology, 53: 279-307.

Bunderson, J. S., \& Sutcliffe, K. M. 2002. Comparing alternative conceptualizations of functional diversity in management teams: Process and performance effects. Academy of Management Journal, 45: 875-893. 
Chatman, J. A., Polzer, J. T., Barsade, S. G., \& Neale, M. A. 1998. Being different yet feeling similar: The influence of demographic composition and organizational culture on work processes and outcomes. Administrative Science Quarterly, 43: 749-780.

Côté, S. 2011. How social class shapes thoughts and actions in organizations. Research in Organizational Behavior, 31: 43-71.

Cox, T. H., Lobel, S. A., \& McLeod, P. L. 1991. Effects of ethnic group cultural differences on cooperative and competitive behavior on a group task. Academy of Management Journal, 34: 827-847.

Crisp, R. J., \& Hewstone, M. 2001. Multiple categorization and implicit intergroup bias: Differential category dominance and the positive-negative asymmetry effect. European Journal of Social Psychology, 31: 45-62.

Crisp, R. J., \& Hewstone, M. 2007. Multiple social categorization. Advances in Experimental Social Psychology, 39: 163-254.

Dahlin, K. B., Weingart, L. R., \& Hinds, P. J. 2005. Team diversity and information use. Academy of Management Journal, 48: 1107-1123.

Dawson, J. F. 2014. Moderation in management research: What, why, when, and how. Journal of Business and Psychology, 29: 1-19.

De Dreu, C. K., Nijstad, B. A., \& van Knippenberg, D. 2008. Motivated information processing in group judgment and decision making. Personality and Social Psychology Review, 12: 22-49.

De Dreu, C. K., \& West, M. A. 2001. Minority dissent and team innovation: the importance of participation in decision making. Journal of Applied Psychology, 86: 1191-1201.

de Wit, F. R., Greer, L. L., \& Jehn, K. A. 2012. The paradox of intragroup conflict: a meta-analysis. Journal of Applied Psychology, 97: 360-390.

DiTomaso, N., Post, C., \& Parks-Yancy, R. 2007. Workforce diversity and inequality: Power, status, and numbers. Annual Review Sociology, 33: 473-501.

Edwards, J. R., \& Lambert, L. S. 2007. Methods for integrating moderation and mediation: a general analytical framework using moderated path analysis. Psychological Methods, 12: 1-22.

Ekman, P.1999. Basic emotions. In T. Dalgleish \& T. Power (Eds.), The handbook of cognition and emotion: 45-60. New York, NY: John Wiley and Sons.

Ekman, P., \& Friesen, W. V. 1974. Nonverbal behavior and psychopathology. In R. J. Friedman \& M. M. Katz (Eds), The psychology of depression: Contemporary theory and research: 203-224. Washington D. C: Winston \& Sons.

Estrada, C. A., Isen, A. M., \& Young, M. J. 1997. Positive affect facilitates integration of information and decreases anchoring in reasoning among physicians. Organizational Behavior and Human Decision Processes, 72: 117-135.

Forgas, J. P. 1995. Mood and judgment: The affect infusion model (AIM). Psychological Bulletin, 117: 39-66.

Forgas, J. P., \& George, J. M. 2001. Affective influences on judgments and behavior in organizations: An information processing perspective. Organizational Behavior and Human Decision Processes, 86: 3-34.

George, J. M., \& Zhou, J. 2007. Dual tuning in a supportive context: Joint contributions of positive mood, negative mood, and supervisory behaviors to employee 
creativity. Academy of Management Journal, 50: 605-622.

Gersick, C.1988. Time and transition in work teams: Toward a model of group development. Academy of Management Journal, 31: 9-42.

Grant, H., \& Dweck, C. S. 2003. Clarifying achievement goals and their impact. Journal of personality and social psychology, 85: 541-553.

Gray, B., \& Kish-Gephart, J. J. 2013. Encountering social class differences at work: How “class work" perpetuates inequality. Academy of Management Review, 38: 670-699.

Guillaume, Y. R., Brodbeck, F. C., \& Riketta, M. 2012. Surface-and deep-level dissimilarity effects on social integration and individual effectiveness related outcomes in work groups: A meta-analytic integration. Journal of Occupational and Organizational Psychology, 85: 80-115.

Guillaume, Y. R., Dawson, J. F., Otaye-Ebede, L., Woods, S. A., \& West, M. A. 2015. Harnessing demographic differences in organizations: What moderates the effects of workplace diversity?. Journal of Organizational Behavior. http://dx.doi.org/10.1002/job.2040.

Harrison, D. A., \& Klein, K. J. 2007. What's the difference? Diversity constructs as separation, variety, or disparity in organizations. Academy of Management Review, 32: 1199-1228.

Homan, A. C., van Knippenberg, D., Van Kleef, G. A., \& De Dreu, C. K. 2007. Interacting dimensions of diversity: Cross-categorization and the functioning of diverse work groups. Group Dynamics: Theory, Research, and Practice, 11: 79-94.

Jackson, S. E., \& Joshi, A. 2011. Work team diversity. In S. Zedeck (Ed.). APA handbook of industrial and organizational psychology: 651-686. Washington, DC: APA.

Jackson, S. E., Joshi, A., \& Erhardt, N. L. 2003. Recent research on team and organizational diversity: SWOT analysis and implications. Journal of Management, 29: 801-830.

James, L. R., Demaree, R. G., \& Wolf, G. 1984. Estimating within-group interrater reliability with and without response bias. Journal of Applied Psychology, 69: 85-98.

Jehn, K. A., Northcraft, G. B., \& Neale, M. A. 1999. Why differences make a difference: A field study of diversity, conflict and performance in workgroups. Administrative Science Quarterly, 44: 741-763.

Jehn, K. A., \& Shah, P. P. 1997. Interpersonal relationships and task performance: An examination of mediation processes in friendship and acquaintance groups. Journal of Personality and Social Psychology, 72: 775-790.

John, O. P., \& Srivastava, S. 1999. The Big Five trait taxonomy: History, measurement, and theoretical perspectives. In L. A. Pervin \& O. P. John (Eds.), Handbook of personality: Theory and research: 102-138. New York: Guilford Press.

Johnson, M. D., Hollenbeck, J. R., Humphrey, S. E., Ilgen, D. R., Jundt, D., \& Meyer, C. J. 2006. Cutthroat cooperation: Asymmetrical adaptation to changes in team reward structures. Academy of Management Journal, 49: 103-119.

Johnson, P. O., \& Neyman, J. 1936. Tests of certain linear hypotheses and their application to some educational problems. Statistical Research Memoirs, 1: 57-93.

Joshi, A., \& Roh, H. 2009. The role of context in work team diversity research: A meta-analytic review. Academy of Management Journal, 52: 599-627.

Kearney, E., Gebert, D., \& Voelpel, S. C. 2009. When and how diversity benefits teams: The 
importance of team members' need for cognition. Academy of Management Journal, 52: 581-598.

Keltner, D., \& Haidt, J. 1999. Social functions of emotions at four levels of analysis. Cognition \& Emotion, 13: 505-521.

Kemper, T. D. 1978. A social interactional theory of emotions. New York: Wiley.

Kirkman, B. L., Chen, G., Farh, J. L., Chen, Z. X., \& Lowe, K. B. 2009. Individual power distance orientation and follower reactions to transformational leaders: A cross-level, cross-cultural examination. Academy of Management Journal, 52: 744-764.

Kish-Gephart, J. J., \& Campbell, J. T. 2015. You don't forget your roots: The influence of CEO social class background on strategic risk taking. Academy of Management Journal, 58: 1614-1636.

Knapp, M. L., Ellis, D. G., \& Williams, B. A. 1980. Perceptions of communication behavior associated with relationship terms. Communications Monographs, 47: 262-278.

Kooij-de Bode, H. J., van Knippenberg, D., \& van Ginkel, W. P. 2008. Ethnic diversity and distributed information in group decision making: The importance of information elaboration. Group Dynamics: Theory, Research, and Practice, 12: 307-320.

Kozlowski, S. W. J., \& Bell, B. S. 2003. Work groups and teams in organizations. In W. C. Borman \& D. R. Ilgen (Eds.). Handbook of psychology: Industrial and organizational psychology: 333-375. New York: Wiley.

Krämer, N. C., \& Winter, S. 2008. Impression management 2.0: The relationship of self-esteem, extraversion, self-efficacy, and self-presentation within social networking sites. Journal of Media Psychology, 20: 106-116.

Kraus, M. W., Piff, P. K., \& Keltner, D. 2009. Social class, sense of control, and social explanation. Journal of Personality and Social Psychology, 97: 992-1004.

Kraus, M. W., Piff, P. K., Mendoza-Denton, R., Rheinschmidt, M. L., \& Keltner, D. 2012. Social class, solipsism, and contextualism: how the rich are different from the poor. Psychological Review, 119: 546-572.

Lazarus, R. S. 1991. Progress on a cognitive-motivational-relational theory of emotion. American Psychologist, 46: 819-834.

Liao, H., Chuang, A., \& Joshi, A. 2008. Perceived deep-level dissimilarity: Personality antecedents and impact on overall job attitude, helping, work withdrawal, and turnover. Organizational Behavior and Human Decision Processes, 106: 106-124.

Loyd, D. L., Wang, C. S., Phillips, K. W., \& Lount Jr, R. B. 2013. Social category diversity promotes premeeting elaboration: The role of relationship focus. Organization Science, 24: 757-772.

Lutz, A., Brefczynski-Lewis, J., Johnstone, T., \& Davidson, R. J. 2008. Regulation of the neural circuitry of emotion by compassion meditation: effects of meditative expertise. PloS one, 3: e1897.

Maas, C. J., \& Hox, J. J. 2005. Sufficient sample sizes for multilevel modeling. Methodology, 1: $86-92$.

Menges, J. I., Kilduff, M., Kern, S., \& Bruch, H. 2015. The awestruck effect: Followers suppress emotion expression in response to charismatic but not individually considerate leadership. The Leadership Quarterly, 26: 626-640.

Mathieu, J. E., Hollenbeck, J. R., van Knippenberg, D., \& Ilgen, D. R. 2016. A century of 
work groups. Journal of Applied Psychology (in press).

Matzler, K., Renzl, B., Müller, J., Herting, S., \& Mooradian, T. A. 2008. Personality traits and knowledge sharing. Journal of Economic Psychology, 29: 301-313.

Mesmer-Magnus, J. R., \& DeChurch, L. A. 2009. Information sharing and team performance: a meta-analysis. Journal of Applied Psychology, 94: 535-546.

Milliken, F. J., \& Martins, L. L. 1996. Searching for common threads: Understanding the multiple effects of diversity in organizational groups. Academy of Management Review, 21: 402-433.

O'Reilly III, C. A., Caldwell, D. F., \& Barnett, W. P. 1989. Work group demography, social integration, and turnover. Administrative Science Quarterly, 34: 21-37.

Park, B., \& Rothbart, M. 1982. Perception of out-group homogeneity and levels of social categorization: Memory for the subordinate attributes of in-group and out-group members. Journal of Personality and Social Psychology, 42: 1051-1068.

Phillips, K. W., Northcraft, G. B., \& Neale, M. A. 2006. Surface-level diversity and decision-making in groups: When does deep-level similarity help? Group Processes \& Intergroup Relations, 9: 467-482.

Preacher, K. J., Curran, P. J., \& Bauer, D. J. 2006. Computational tools for probing interactions in multiple linear regression, multilevel modeling, and latent curve analysis. Journal of Educational and Behavioral Statistics, 31: 437-448.

Ridgeway, C. 1991. The social construction of status value: Gender and other nominal characteristics. Social Forces, 70: 367-386.

Sanchez-Burks, J., \& Huy, Q. N. 2009. Emotional aperture and strategic change: The accurate recognition of collective emotions. Organization Science, 20: 22-34.

Schwarz, N., Bless, H., \& Bohner, G. 1991. Mood and persuasion: Affective states influence the processing of persuasive communications. Advances in Experimental Social Psychology, 24: 161-199.

Schwarz, N., \& Clore, G. L. 2003. Mood as information: 20 years later. Psychological Inquiry, 14: 296-303.

Selig, J. P., \& Preacher, K. J. 2008. Monte Carlo method for assessing mediation: An interactive tool for creating confidence intervals for indirect effects [Computer software].

Seo, M. G., \& Barrett, L. F. 2007. Being emotional during decision making—good or bad? An empirical investigation. Academy of Management Journal, 50: 923-940.

Simons, T., Pelled, L. H., \& Smith, K. A. 1999. Making use of difference: Diversity, debate, and decision comprehensiveness in top management teams. Academy of Management Journal, 42: 662-673.

Srikanth, K., Harvey, S., \& Peterson, R. 2016. A Dynamic Perspective on Diverse Teams: Moving from the Dual-Process Model to a Dynamic Coordination-based Model of Diverse Team Performance. The Academy of Management Annals, 10: 453-493.

Stangor, C., Lynch, L., Duan, C., \& Glas, B. 1992. Categorization of individuals on the basis of multiple social features. Journal of Personality and Social Psychology, 62: 207-218.

Stasser, G., \& Titus, W. 1985. Pooling of unshared information in group decision making: Biased information sampling during discussion. Journal of Personality and Social 
Psychology, 48: 1467-1478.

Tajfel, H., \& Turner, J. C. 1979. An integrative theory of intergroup conflict. In W. Austin \& $\mathrm{S}$. Worchel (Eds.), The social psychology of intergroup relations: 33-48. Pacific Grove, CA: Brooks/Cole.

Tropp, L. R., \& Pettigrew, T. F. 2005. Relationships between intergroup contact and prejudice among minority and majority status groups. Psychological Science, 16: 951-957.

Tsui, A. S., Egan, T. D., \& O'Reilly III, C. A. 1992. Being different: Relational demography and organizational attachment. Administrative Science Quarterly, 47: 549-579.

Turner, J. C., Hogg, M. A., Oakes, P. J., Reicher, S. D., \& Wetherell, M. S. 1987. Rediscovering the social group: A self-categorization theory. New York: Basil Blackwell.

Van Der Vegt, G. S., \& Bunderson, J. S. 2005. Learning and performance in multidisciplinary teams: The importance of collective team identification. Academy of Management Journal, 48: 532-547.

Van Knippenberg, D., De Dreu, C. K., \& Homan, A. C. 2004. Work group diversity and group performance: an integrative model and research agenda. Journal of Applied Psychology, 89: 1008-1022.

van Ginkel, W. P., \& van Knippenberg, D. 2009. Knowledge about the distribution of information and group decision making: When and why does it work? Organizational Behavior and Human Decision Processes, 108: 218-229.

van Knippenberg, D., \& Mell, J. N. 2016. Past, present, and potential future of team diversity research: From compositional diversity to emergent diversity. Organizational Behavior and Human Decision Processes, 136: 135-145.

Van Vianen, A. E., \& De Dreu, C. K. 2001. Personality in teams: Its relationship to social cohesion, task cohesion, and team performance. European Journal of Work and Organizational Psychology, 10: 97-120.

Wang, S., \& Noe, R. A. 2010. Knowledge sharing: A review and directions for future research. Human Resource Management Review, 20: 115-131.

Watson, D., Clark, L. A., \& Tellegen, A. 1988. Development and validation of brief measures of positive and negative affect: the PANAS scales. Journal of Personality and Social Psychology, 54: 1063-1070.

Webber, S. S., \& Donahue, L. M. 2001. Impact of highly and less job-related diversity on work group cohesion and performance: A meta-analysis. Journal of Management, 27: 141-162.

Wegge, J., \& Schmidt, K.-H. 2009. The impact of age diversity in teams on group performance and health. In A. Antoniou, C. L. Cooper, G. P. Chrousus, C. D. Spielberger \& M. W. Eysenck (Eds.), Handbook of managerial behavior and occupational health: 79-94. Cheltenham Glos, UK: Edward Elgar Publishing.

Williams, K. Y., \& O'Reilly III, C. A. 1998. A review of 40 years of research. Research in Organization Behavior, 20: 77-140. 
TABLE 1

Mean, Standard Deviation, and Correlations

\begin{tabular}{|c|c|c|c|c|c|c|c|c|c|c|c|c|c|c|c|c|c|c|c|c|c|c|c|c|c|}
\hline & Mean & SD & 1 & 2 & 3 & 4 & 5 & 6 & 7 & 8 & 9 & 10 & 11 & 12 & 13 & 14 & 15 & 16 & 17 & 18 & 19 & 20 & 21 & 22 & 23 \\
\hline 1 & 1.59 & .69 & & & & & & & & & & & & & & & & & & & & & & & \\
\hline 2 & 1.27 & .50 & $.75^{* *}$ & & & & & & & & & & & & & & & & & & & & & & \\
\hline 3 & 6.72 & 5.66 & .04 & .00 & & & & & & & & & & & & & & & & & & & & & \\
\hline 4 & .40 & .10 & -.11 & -.14 & .02 & & & & & & & & & & & & & & & & & & & & \\
\hline 5 & .24 & .19 & .22 & .19 & .00 & -.04 & & & & & & & & & & & & & & & & & & & \\
\hline 6 & 4.90 & .44 & .03 & .02 & -.20 & .14 & .02 & & & & & & & & & & & & & & & & & & \\
\hline 7 & 2.92 & .58 & -.08 & -.05 & .06 & .06 & .05 & $-.51^{* *}$ & & & & & & & & & & & & & & & & & \\
\hline 8 & .90 & .30 & -.06 & -.13 & .05 & .04 & $-.24^{*}$ & $-.43^{* *}$ & .13 & & & & & & & & & & & & & & & & \\
\hline 9 & 1.21 & .37 & -.01 & -.12 & -.17 & .10 & .11 & -.18 & $.39^{* *}$ & $.28^{*}$ & & & & & & & & & & & & & & & \\
\hline 10 & 4.78 & .37 & .06 & .01 & -.03 & -.03 & .21 & $.27^{*}$ & $-.25^{*}$ & -.22 & -.10 & & & & & & & & & & & & & & \\
\hline 11 & 2.09 & .46 & -.06 & -.03 & .06 & -.03 & -.13 & $-.23^{*}$ & $.34^{* *}$ & .20 & .09 & $-.58^{* *}$ & & & & & & & & & & & & & \\
\hline 12 & 6.06 & .32 & -.01 & .03 & .14 & -.11 & -.09 & .03 & -.20 & .09 & -.10 & -.02 & .06 & & & & & & & & & & & & \\
\hline 13 & .71 & .27 & -.03 & .05 & -.11 & .02 & -.04 & -.03 & .02 & -.02 & .14 & -.08 & -.10 & $-.55^{* *}$ & & & & & & & & & & & \\
\hline 14 & 5.04 & .32 & .08 & .09 & -.01 & -.13 & -.03 & .02 & .04 & -.19 & .04 & .02 & .08 & $.26^{*}$ & -.02 & & & & & & & & & & \\
\hline 15 & .67 & .24 & .12 & -.07 & -.04 & -.09 & .15 & $.23^{*}$ & -.21 & .03 & .02 & .18 & -.08 & .01 & .03 & -.20 & & & & & & & & & \\
\hline 16 & 4.52 & .45 & .11 & .15 & .03 & .14 & .06 & .12 & .01 & -.08 & .05 & -.05 & .00 & $.30^{* *}$ & $-.23^{*}$ & .03 & -.09 & & & & & & & & \\
\hline 17 & .95 & .27 & .06 & .08 & .08 & -.07 & .16 & $-.28^{*}$ & .01 & -.06 & -.13 & -.13 & .02 & .00 & .10 & -.07 & .10 & -.19 & & & & & & & \\
\hline 18 & 5.02 & .81 & .04 & -.09 & .03 & .05 & .09 & $.29^{*}$ & $-.26^{*}$ & -.11 & -.07 & $.26^{*}$ & -.13 & -.09 & -.03 & -.08 & .13 & .01 & -.03 & & & & & & \\
\hline 19 & 3.98 & .82 & -.05 & -.09 & .06 & .07 & .01 & $.31^{* *}$ & $-.32^{* *}$ & .01 & -.03 & $.23^{*}$ & -.08 & .01 & .06 & -.01 & .12 & .03 & -.03 & $.63^{* *}$ & & & & & \\
\hline 20 & .85 & .31 & .09 & .06 & -.12 & .13 & $-.35^{*}$ & .00 & .00 & .22 & .09 & $-.27^{*}$ & .16 & -.16 & .19 & -.03 & .04 & -.15 & -.19 & -.10 & -.09 & & & & \\
\hline 21 & 094 & .39 & -.08 & .00 & -.09 & .04 & -.08 & -.15 & $.26^{*}$ & .13 & .15 & $-.44^{* * *}$ & $.65^{* *}$ & .06 & -.01 & .12 & -.06 & .06 & .02 & -.14 & -.14 & $.37^{* *}$ & & & \\
\hline 22 & 4.01 & .80 & .09 & -.08 & .06 & .15 & .17 & .05 & -.15 & -.02 & -.07 & $.28^{*}$ & -.06 & -.16 & -.08 & -.19 & $.23^{*}$ & -.12 & -.11 & .12 & -.02 & -.08 & -.19 & & \\
\hline 23 & 4.94 & .65 & .01 & .03 & -.01 & .07 & .00 & $.36^{* *}$ & $-.41^{* *}$ & -.06 & -.17 & .20 & $-.30^{*}$ & $-.28^{*}$ & .20 & -.13 & .07 & -.06 & -.08 & $.43^{* *}$ & $.49^{* *}$ & -.11 & $-.30^{* *}$ & .01 & \\
\hline 24 & 1.42 & .20 & -.14 & -.16 & .10 & -.12 & .05 & .10 & -.03 & .12 & -.02 & -.08 & -.10 & .07 & -.08 & -.13 & .12 & -.09 & -.03 & .02 & -.05 & .05 & -.16 & -.08 & .08 \\
\hline
\end{tabular}


Notes: Variable names: 1. Age diversity; 2. Tenure diversity; 3. CAT diversity; 4. Gender diversity; 5. Major diversity; 6. Positive affectivity (group mean); 7. Negative affectivity (group mean); 8. Positive affectivity diversity; 9. Negative affectivity diversity; 10. Positive emotion (group mean); 11. Negative emotion (group mean); 12. Learning goal orientation (group mean); 13. Learning goal orientation diversity; 14. Openness (group mean); 15. Openness diversity; 16. Extraversion (group mean); 17. Extraversion diversity; 18. Team cohesion; 19. Communication quality; 20. Positive emotion diversity; 21. Negative emotion diversity; 22. Social class homogeneity; 23. Team information sharing; 24. Team performance.

$\mathrm{N}=75$;

$* \mathrm{p}<.05 ; * * \mathrm{p}<.01 ;$ two-tailed test. 
TABLE 2

The Results of the Regression on Team Information Sharing and Team Performance

\begin{tabular}{|c|c|c|c|c|c|c|}
\hline & \multicolumn{4}{|c|}{ DV: Team information sharing } & \multicolumn{2}{|c|}{ DV: Team performance } \\
\hline & Model 1 & Model 2 & Model 3 & Model 4 & Model 5 & Model 6 \\
\hline Intercept & $4.96 * *$ & $4.94 * *$ & $4.91 * *$ & $4.96^{* * *}$ & $1.42 * *$ & $1.41^{* *}$ \\
\hline \multicolumn{7}{|l|}{ Control variables } \\
\hline Instructor 1 & -.04 & -.12 & -.12 & -.15 & .00 & .04 \\
\hline Instructor 2 & -.03 & -.13 & -.00 & -.06 & -.02 & .02 \\
\hline Gender diversity & .05 & .05 & .03 & .04 & -.05 & $-.05^{\dagger}$ \\
\hline Age diversity & -.08 & -.10 & -.11 & -.15 & -.03 & -.03 \\
\hline Tenure diversity & .17 & $.18^{\dagger}$ & .16 & $.22 *$ & -.02 & -.04 \\
\hline Major diversity & -.03 & -.01 & .03 & .04 & .04 & .04 \\
\hline Positive affectivity (group mean) & .05 & .01 & .05 & .01 & .06 & .08 \\
\hline Positive affectivity diversity & .09 & .11 & .08 & .12 & .04 & .03 \\
\hline Negative affectivity (group mean) & $-.17^{\dagger}$ & $-.20^{*}$ & -.17 & $-.21 *$ & .04 & .03 \\
\hline Negative affectivity diversity & -.07 & -.06 & -.07 & -.01 & -.01 & .01 \\
\hline Positive emotions (group mean) & -.13 & -.08 & -.10 & -.03 & -.04 & -.05 \\
\hline Negative emotions (group mean) & $-.16^{\dagger}$ & $-.14^{\dagger}$ & -.15 & -.10 & -.02 & -.01 \\
\hline Learning goal orientation (group mean) & $-.26 * *$ & $-.28 * *$ & $-.24 *$ & $-.34 * *$ & .03 & .04 \\
\hline Learning goal orientation diversity & -.03 & -.04 & -.03 & -.10 & -.01 & -.02 \\
\hline Openness (group mean) & .01 & .01 & .01 & .03 & -.01 & -.02 \\
\hline Openness diversity & .02 & .02 & -.00 & .04 & .00 & .01 \\
\hline Extraversion (group mean) & -.01 & -.01 & .01 & .05 & -.02 & -.02 \\
\hline Extraversion diversity & -.10 & -.11 & -.08 & -.11 & .02 & .03 \\
\hline Team cohesion & .06 & .08 & .06 & .06 & .02 & .02 \\
\hline Team communication quality & $.25^{*}$ & $.20 * *$ & $.24^{*}$ & $.17 *$ & -.04 & -.05 \\
\hline \multicolumn{7}{|l|}{ Predictors } \\
\hline Positive emotion diversity & $-.14^{\dagger}$ & $-.15^{\dagger}$ & & & .04 & .05 \\
\hline Negative emotion diversity & & & -.03 & -.06 & -.04 & -.06 \\
\hline Social class homogeneity & & -.11 & & $-.19^{*}$ & & -.01 \\
\hline Positive emotion diversity $*$ social class homogeneity & & $.13 *$ & & & & \\
\hline Negative emotion diversity * social class homogeneity & & & & $.20 * *$ & & \\
\hline Information sharing & & & & & .03 & .04 \\
\hline Information sharing * social class homogeneity & & & & & & $-.06^{*}$ \\
\hline Adjusted $R^{2}$ & .39 & .42 & .35 & .44 & $\rho^{\mathrm{a}}$ & .01 \\
\hline$\Delta R^{2}$ & $.03^{\dagger}$ & $.03 *$ & .00 & $.09 * *$ & .01 & $.08^{*}$ \\
\hline
\end{tabular}

Notes: $N=75 ;^{\dagger} p<.10, * p<.05 ; * * p<.01$; a: the adjusted $R^{2}$ is not available because the value is negative. 


\section{FIGURE 1}

\section{Conceptual Model}

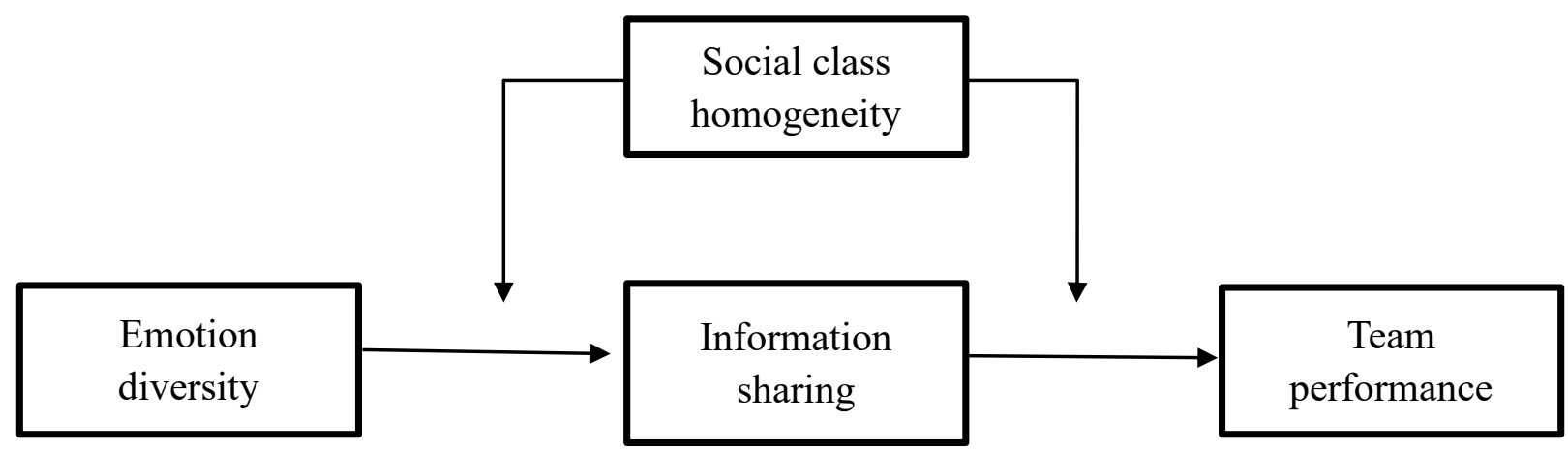

FIGURE 2

The Interaction Effect between Positive Emotion Diversity and Social Class Homogeneity on Team Information Sharing

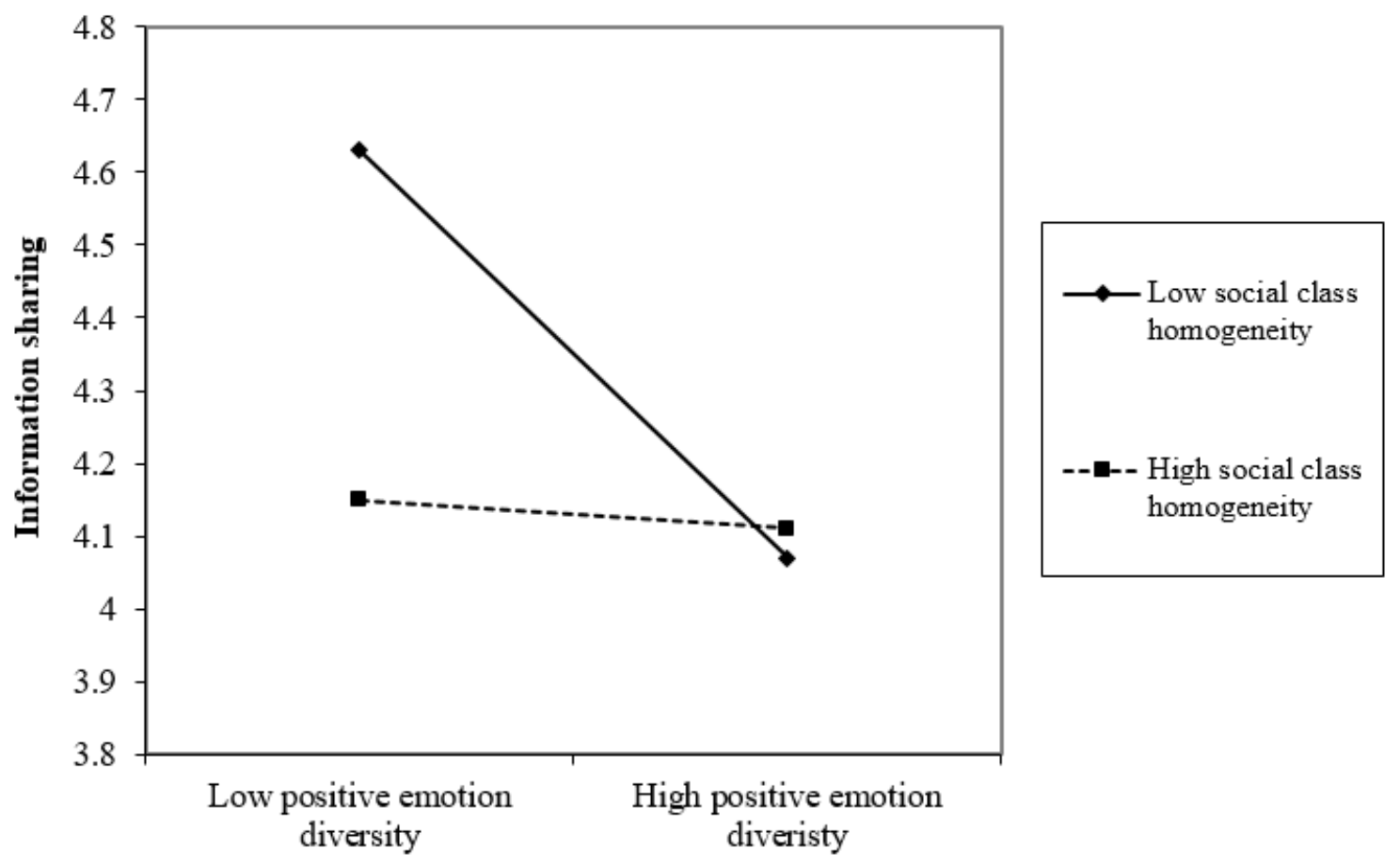


FIGURE 3

The Interaction Effect between Negative Emotion Diversity and Social Class Homogeneity on Team Information Sharing

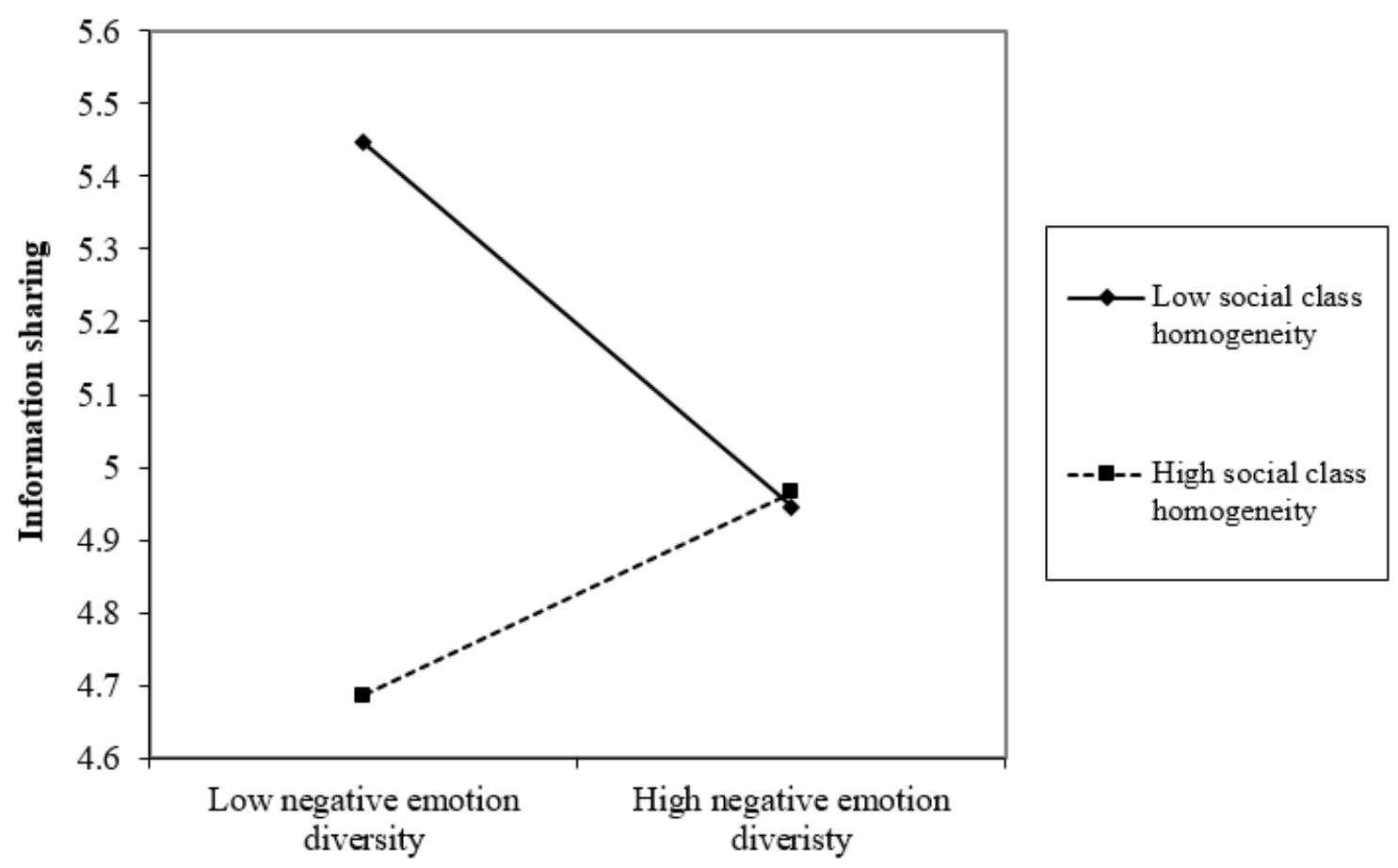

FIGURE 4

The Interaction Effect between Team Information Sharing and Social Class Homogeneity on Team Performance

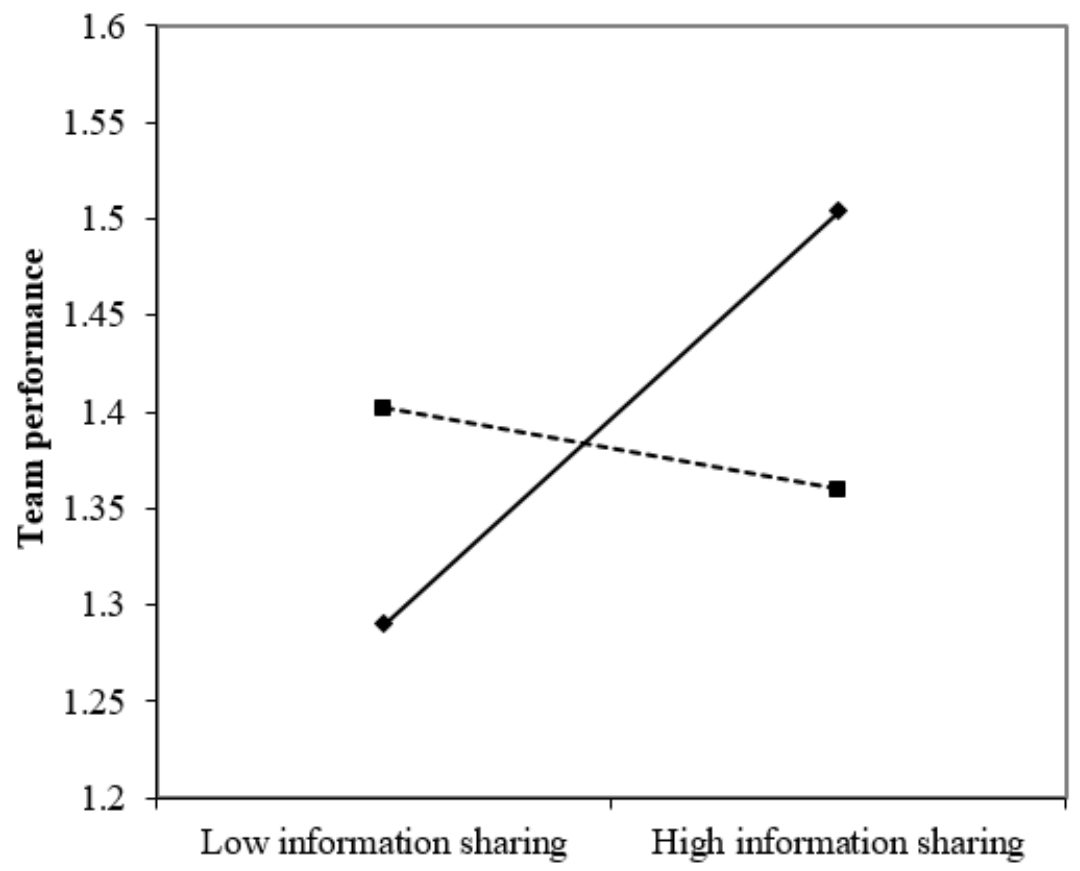

$\longrightarrow$ Low social class homogeneity

---1-- High social class homogeneity 